\title{
Комбикорма с пробиотиками: коррекция дозы в зависимости от срока хранения
}

Гулюшин С.Ю., кандидат биологических наук, зав. лабораторией микотоксикологии

ФГБНУ Федеральный научный центр «Всероссийский научно-исследовательский и технологический институт птицеводства» Российской академии наук (ФНЦ «ВНИТИП» РАН)

\begin{abstract}
Аннотащия: Результаты исследования по въоду пробиотических лактобацилл 6 комбикорма с разным уровнем токсичности быявили тенденцию снижения их общего количества 6 процессе хранения кормов, начиная с первого дня, 6 зависимости от уровня токсичности корма, причем 6 течение 2-го месяца хранения это снижение при бсех уровнях токсичности становилось лабинообразным. Естественную убыль пробиотической микрофлоры 6 процессе предполагаемого продолжительного хранения кормоб рекомендуется компенсировать путем в6ода дополнительного количества пробиотика из расчета 5\% (по массе) на каждую неделю хранения. Недоброкачественные комбикорма со сроком хранения сбыше 1 месяиа иелесообразно не использобать 6 кормлении птиць.
\end{abstract}

Ключебые слова: микотоксины, пробиотические препараты, лактобацилль, комбикорма, срок хранения.

Введение. Проблема микотоксикозов является актуальным вопросом современности, наносящим ощутимый урон всей отрасли птицеводства. В рамках данного сообщения мы не будем раскрывать все аспекты и предпосылки возникновения хронических отравлений - они сложны и многочисленны. Отметим лишь, что сколь разнообразны формы и причины проявления патологии, выражающейся каскадом взаимно обусловленных факторов, столь же разнообразны и «точки восстановления» физиологического статуса организма. Поэтому, используя в коррекционных целях разные группы биологически активных веществ (отдельно или в сочетанном режиме), представляется возможным снизить негативный эффект, при условии, что применение данных препаратов будет адекватно силе негативного действия самих микотоксинов [1-3].
Остановимся более подробно на позитивном эффекте микрофлоры, точнее, специализированной микрофлоры, действие которой направлено на деструкцию микотоксинов в ЖКТ птицы. Ранее проведенные нами исследования выявили способность некоторых форм лактобацилл направленно «разрушать» тот или иной токсин, доказана возможность существенного усиления этих свойств у бактерий, используя приемы накопительной селекции, а новые штаммы по силе антитоксического эффекта превосходят большинство традиционно применяемых кормовых добавок (в т.ч. энтеросорбентов), оказывая общее оздоравливающее действие. Другими словами, наличие «сильных» бактерий и их обоснованный уровень ввода в корм - перспективный прием решения проблемы в целом $[4,5]$.
Вместе с тем, говоря о дозах ввода того или иного препарата как важном критерии силы их биологического действия, нужно помнить, что применительно к живой микрофлоре здесь имеется несколько технологических нюансов. С одной стороны, микроорганизмы-деструкторы - это сравнительно дорогой класс биологически активных веществ, требующий рачительного применения: низкие уровни их ввода не обеспечат должного антитоксического эффекта, а завышенный ввод («чтобы наверняка») будет сопряжен с экономическими издержками. Следовательно, рекомендуемый уровень ввода пробиотика в корм всегда должен соотноситься С фоном токсичности рационов и соответствовать рекомендациям производителей [6,7]. С другой стороны, обычные комбикорма с характерным набором макро- и микро- 
компонентов в совокупности с атмосферным кислородом воздуха являются крайне агрессивной средой даже для лиофилизированных экзогенных микроорганизмов. Убыль активных форм, особенно в процессе длительного хранения, здесь многократно превышает убыль других относительно неустойчивых компонентов, например, витаминов. К тому же, в некоторых случаях токсины корма могут непосредственно влиять на биообьекты, более интенсивно инактивируя их по сравнению с чистыми рационами. В таких случаях показан гарантированный «сверх-ввод» препарата, учитывающий возможный срок хранения корма перед скармливанием: чем дольше хранение, тем выше уровень ввода добавки $[8,9]$.

Таким образом, рассматривая данную проблему в комплексе, нами была проведена экспериментальная работа, имеющая целью изучить динамику сохранения молочнокислых микроорганизмов в комбикормах и выявить эффективные уровни ввода пробиотиков в корма в зависимости от срока их хранения.

Материал и методика исследований. Исследования проводились в лаборатории микотоксикологии ФНЦ «ВНИТИП» РАН, где на начальном этапе была приготовлена техническая кормосмесь (ГОСТ 18221-2018) умеренной степени токсичности (3-5 ПДК).

Затем этот комбикорм был поделен на три части, имитирующие слабо-, умеренно- и сильно-токсичные рационы; в каждую из них были внесены новые штаммы лактобацилл с высокой устойчивостью К микотоксинам из расчета 106, $10^{7}$ и $10^{8} \mathrm{KOE} / г$ соответственно.
Толерантные фоормы лактобацилл были предварительно размножены чашечным методом, суспендированы в физраствор, нанесены на органический носитель (отруби) и подсушены. Полученные новые пробиотические препараты-премиксы методом ступенчатого смешивания включались в комбикорма на уровне 0,5\%, обеспечивающем достаточно равномерное содержание бактериальной микрофлоры в общей массе кормов.

В последующем все кормосмеси подвергались хранению в течение 2 месяцев в условиях, схожих со стандартным температурно-влажностным режимом в птичнике (температура $15-25^{\circ} \mathrm{C}$, относительная влажность воздуха 65-75\%) . Непосредственно после приготовления и с интервалом в 15 дней от начала хранения производили забор образцов корма, где определяли текущий уровень молочнокислой микрофлоры. Обобщенные данные подвергались статистическому анализу.

Результаты исследований и их обсуждение. Уже на следующий день после приготовления опытных кормосмесей уровень молочнокислых бактерий в них снижался на 5-8\% от исходного содержания в премиксе (табл. 1). Объяснить это можно тем, что в нашем эксперименте использовались живые культуры лактобацилл, которые в процессе сушки и смешивания корма частично инактивировались под влиянием механических факторов. Вместе с тем, при использовании защищенных (покрытых оболочкой) или лиофильно-высушенных форм лактобацилл такой эффект наблюдается в меньшей степени, что необходимо учитывать в условиях практики. Таким образом, в большинстве случаев приоритет должен отдаваться стабилизированным формам антитоксических пробиотиков, рекомендованных к применению в кормопроизводстве.

Далее в процессе хранения нисходящая динамика снижения содержания молочнокислых микроорганизмов была выявлена во всех кормосмесях, независимо от исходного их содержания. В большей мере это было характерно для комбикормов с самым низким уровнем ввода биопрепарата. То есть, корректировку продуктивности на слоботоксичных рационах целесообразно проводить дополнительным включением пробиотика из расчета 5\% сверх нормы ввода на каждую предполагаемую неделю хранения. Особенно это актуально, когда корма готовятся сразу на всю фазу или определенный производственный цикл.

Таблица 1. Содержание пробиотической микрофлоры в кормах с вводом пробиотических препаратов в зависимости от срока хранения

Уровень молочнокислой микрофлоры, КОЕ/г

\begin{tabular}{lccccc}
\multicolumn{1}{c}{\begin{tabular}{c}
\multicolumn{1}{c}{ Комбикорм } \\
(ввод пробиотика)
\end{tabular}} & \multicolumn{4}{c}{ Уровень молочнокислой микрофлоры, КОЕ/г } \\
\cline { 2 - 6 } & $\mathbf{1}$ день & $\mathbf{1 5}$ день & $\mathbf{3 0}$ день & $\mathbf{4 5}$ день & $\begin{array}{c}\mathbf{6 0 - 6 1} \\
\text { день }\end{array}$ \\
\hline $\begin{array}{l}\text { Слаботоксичный } \\
\left(10^{6} \mathrm{KOE} / \text { г }\right)\end{array}$ & $9,29 \times 10^{5}$ & $7,79 \times 10^{5}$ & $5,54 \times 10^{5}$ & $2,02 \times 10^{5}$ & $3,37 \times 10^{4}$ \\
\hline $\begin{array}{l}\text { Умеренно-токсичный } \\
\left(10^{7} \mathrm{KOE} / \text { г) }\right.\end{array}$ & $9,37 \times 10^{6}$ & $8,06 \times 10^{6}$ & $6,05 \times 10^{6}$ & $3,39 \times 10^{6}$ & $7,90 \times 10^{5}$ \\
\hline $\begin{array}{l}\text { Сильно-токсичный } \\
\left(10^{8} \mathrm{KOE} / \text { г }\right)\end{array}$ & $9,51 \times 10^{7}$ & $8,53 \times 10^{7}$ & $7,25 \times 10^{7}$ & $4,08 \times 10^{7}$ & $1,65 \times 10^{7}$
\end{tabular}


В умеренно-токсичных рационах, которые подверглись бы хранению, и где предполагается изначально более высокий ввод пробиотика (107 КОЕ/г корма), в абсолютном исчислении погибнет большее количество молочнокислых микроорганизмов, однако в относительном исчислении этот спад менее выражен. Здесь компенсаторный ввод препарата показан на уровне $5 \%$ на каждые 2 недели вынужденной отсрочки его скармливания, но при неблагоприятных условиях возможен и больший процент ввода.

Начиная со второго месяца хранения имел место достоверный лавинообразный спад концентрации лактобацилл (на 3555\%), достигающий величин почти полной инактивации (в 6-28 раз) к концу 2-месячного периода хранения. Восполнять ввод пробиотических препаратов на таком уровне крайне нерационально. Кроме того, сильный разогрев, сопутствующие процессы перекисного окисления липидов и бурное развитие плесеней способствуют накоплению в корме иных факторов, негативно влияющих на организм птицы, что лишь усугубляет действие микотоксинов. Потенциально опасные (токсичные) полнорационные комбикорма не рекомендуется хранить свыше 1 месяца, они подлежат утилизации.

Заключение. Включение В загрязненный комбикорм пробиотиков позволяет смягчить последствия хронических микотоксикозов. Для слаботоксичных рационов это должны быть уровни не ниже $10^{6} \mathrm{KOE} / г$, для умереннозагрязненных - 107-10 KOE/г (в за- висимости от свойств конкретного препарата). Причем предпочтение во всех случаях должно отдаваться специализированным антитоксическим средствам, применяемым в обоснованных дозах с актуальным сроком годности и под контролем микробиологических методов оценки равномерности их внесения в кормосмесь.

В случаях, когда речь идет о жидких формах либо об экспериментальных видах пробиотиков, их ввод в корма должен осуществляться с запасом не менее 5-10\% (по массе). Сухие коммерческие пробиотики, как правило, являются физически стабильной субстанцией и не требуют превышения рекомендуемых уровней ввода.

В зависимости от предполагаемого периода хранения готовых кормосмесей ввод препаратов на стадии приготовления должен быть увеличен на 5\% на каждую полную предполагаемую неделю хранения. Комбикорма с периодом хранения свыше 1 месяца должны быть ограничены в использовании в птицеводстве изза необратимых процессов, происходящих в них, независимо от их исходного качества.

\section{Литература}

1. Брылин, А.П. Влияние микотоксинов на эпизоотическое благополучие, иммунитет и производство экологически безопасной продукции птицеводства // Птицеводство. - 2019 . - №5. С. 57-64.

2. Иванов, А.В. Микотоксины (в пищевой цепочке) / А.В. Иванов, В.И. Фисинин, М.Я. Тремасов, К.Х. Папуниди. - М.: Росинформагротех, 2012. - 136 с.
3. Малков, М.А. Микотоксины стратегия устранения их влияния на организм сельскохозяйственных животных и птицы / М.А. Малков, В.В. Богомолов, Т.В. Данькова, К.А. Краснов // Технология животноводства. - 2010. - №1-2. - С. 4-5. 4. Гулюшин, С. Пробиотики при микотоксикозах: энзимы - главный критерий / С. Гулюшин, Е. Елизарова, А. Долгорукова // Комбикорма. - 2018. - №12. - С. 71-73.

5. Гулюшин, С.Ю. Пробиотики при микотоксикозах: правильно оцениваем препараты / С.Ю. Гулюшин, Е.В. Елизарова // Птицеводство. - 2017. - №1 1. - С. 23-25. 6. Казарян, Р.В. Перспективные направления применения пробиотиков для создания полифункциональных кормовых добавок / Р.В Казарян, А.С. Бородихин, М.В. Лукьяненко, А.Д. Ачмиз, А.Н. Матвиенко // Новые технологии. - 2018.- №2. - С. 116-121.

7. Нуралиев, Е.Р. Диагностика, лечение и профилактика токсикоза птиц, вызванного микотоксинами / Е.Р. Нуралиев, И.И. Кочиш, А.Л. Киселев, М.П. Семененко, Л.Ж. Тлеуова, Р.И. Шарипов // Ветеринария (Казахстан). - 2014.№4-5. - С. 69-77.

8. Шкуратова, И. Пробиотики против микотоксикозов/ И. Шкуратова, И. Лебедева, М. Ряпосова, И. Коноплева, П. Бусыгин // Животноводство России. - 2017. №1. - С. 52-54.

9. Методические рекомендации по кормлению сельскохозяйственной птицы / Ш.А. Имангулов, И.А. Егоров, Т.М. Околелова [и др.]. - Сергиев Посад: ВНИтИП, 2009. - 144 c.

Для контакта с автором:

Гулюшин Сергей Юрьевич

E-mail: micotox@mail.ru 


\title{
Supplementation of Feeds with Probiotics Requires Adjustment of the Dose to the Expected Storage Term
}

\author{
Gulyushin S.Yu. \\ Federal Scientific Center "All-Russian Research and Technological Institute of Poultry" \\ of Russian Academy of Sciences
}

Summary: The trial with the inclusion of mycotoxin-neutralizing probiotic Lactobacilli strain into the compound feeds with different toxicity level with the subsequent storage of the supplemented feeds evidenced the trend to gradual decrease in the concentrations of Lactobacilli during the first month of storage since the very first day after the inclusion, with the intensity depending on the toxicity of feed. This decrease became exponential during the second month of the storage with all toxicity levels. The natural decrease in the concentration of probiotic microorganisms in the stored feeds could be compensated by the increased amount of the initially added probiotic (by 5\% per each expected week of the subsequent storage). The use of feeds stored for more than 1 month is not recommended due to considerably impaired quality.

Keywords: mycotoxins, probiotics, Lactobacilli, compound feeds, storage term. 